\title{
Statistical Modeling of Pomegranate (Punica granatum L.) Fruit with Some Physical Attributes
}

\author{
Yaser Siah Mansouri ${ }^{1 *}$, Javad Khazaei ${ }^{1}$, Seyed Reza Hassan Beygi ${ }^{1}$ and Seyed Saeid Mohtasebi ${ }^{2}$
}

${ }^{1}$ Department of Agrotechnology, College of Abuoreihan, University of Tehran, Tehran, Iran

${ }^{2}$ Department of Agricultural Machinery, Faculty of Agricultural Engineering and Technology, University of Tehran, Karaj, Iran

\begin{abstract}
In this study mass and surface area of pomegranate fruit were predicted with using different physical characteristics in linear models classified as follows: (1) Single or multiple variable regressions of pomegranate dimensional characteristics, (2) Single or multiple variable regressions of pomegranate projected areas, (3) Single regression of pomegranate mass based on measured (actual) volume and volumes of shapes assumed (oblate spheroid and ellipsoid). The results showed that in the first classification of single variable mass modeling of pomegranate based on dimension, the highest determining coefficient was obtained as $R^{2}=0.95$ based on geometric mean diameter $\mathrm{M}=-528+$ 10.7 Dg while that was as $\mathrm{R}^{2}=0.96$ for multiple variable models. Also, there was a very good relationship between mass and measured volume of pomegranates for the two varieties with $R^{2}$ as 0.97 (highest $R^{2}$ value among all the models). At least, the models which predict mass of pomegranates based on estimated volume, the shape of pomegranates considered as spheroid and elliptical were found to be the most appropriate models.
\end{abstract}

Keywords: Mass modeling; Pomegranate fruit; Physical attributes; Peeling; Grading

\section{Introduction}

New industrial machinery development has traditionally required extensive research and development before a final design is selected. Agricultural crops and food products have several unique characteristics which set them different from engineering materials. These properties determine the quality of the fruit and identification of correlation among in these properties makes quality control easier [1]. Physical characteristics of agricultural products are the most important parameters in design of grading, conveying, processing and packaging systems [2]. As an instance, slat conveyor system for displacing of fruits can be designed by fruit size and weight. These features in grading fruit based on weight or size is important in packing and handling machine. Therefore, the relationship between weight and geometric attributes is needed [3]. Pomegranate fruit has been cultivated extensively in Iran, India and some parts in the U.S.A (California), China, Japan and Russia [4-6] but No published articles were found in the literature that described of pomegranate processing machine associated with physical attributes and other engineering properties of fruit. However, a number of patents have been issued. For horticultural commodities, dimensions (length, diameter, thickness) are widely used properties to describe them. Frequently, all cases raw product grades are based on weight [7]. Size and shape determine the number of fruits that can be placed in containers with given size in conveyor system or packing machines. Volume and surface area could be beneficial in proper prediction drying rates and hence drying time in the dryer. The conventional utilization of wild pomegranate fruit lies in the drying seeds along with pulp (arils), which constitute the product "Anardana" [8]. The dehydrated arils are acidic (7.8-15.4\%) and help in improving mouth-feel and digestion. Many studies have reported on the physical properties of fruits, such as wild plum [9], cornelian cherry [10,11], rose fruit [12], fresh okra fruit [13], cherry laurel [14,15], orange [16], berries [17], Juniperus drupacea fruit [18]. Al- Maiman and Ahmad, (2002) studied the physical properties of pomegranate and found models of predicting fruit mass while employing dimensions, volume and surface areas. Knowing the diameter or weight of a fruit, its surface area may be calculated using empirical equations, or read from an appropriate plot $[3,19,20]$ with mass modeling several cultivars of the pomegranate fruit determined models for predicting other properties for grading that can not be enough for studies and design of a suitable machine for pomegranate processing.

The objective of this study was to determine the most suitable model for predicting pomegranate fruit mass by its geometrical attributes and evaluation with similar studies. This information can be used in the design and development of slat conveyor mechanisms for suitable transport with minimal damage to fruits.

\section{Material and Method}

The Iranian pomegranate cultivars consisted of malas saveh and Hondos yal abad were obtained from orchard located in Saveh, Iran (from markazi Province) in October 2009. The 77 fruits of each variety were tested in the Biophysical laboratory and Biological laboratory of University of Tehran, Karaj, Iran. The physical properties of pomegranate such as mass, volume, dimensions and projected area were measured. The samples of the fruits were weighted and dried in an oven at a temperature of $75^{\circ} \mathrm{C}$ for $72 \mathrm{~h}$ and then weight loss on drying to final content weight was recorded as moisture content [21]. The remaining material was kept in cold storage at $5{ }^{\circ} \mathrm{C}$ until use. Fruit mass (M) was determined with an electronic balance with $\pm 0.01 \mathrm{~g}$ sensitivity. To determine the average size of the fruits, three linear dimensions namely as length, width and thickness were measured by using a digital caliber with $\pm 0.01 \mathrm{~mm}$ sensitivity. Volume (V) was determined by the water displacement method [22]. The geometric mean diameter $(D g)$ and surface areas $(S)$ and sphericity were determined by using following formula [22], respectively:

*Corresponding author: $\mathrm{m}$, Department of Agrotechnology, College of Abuoreihan, University of Tehran, Tehran, Iran, Tel: +98-937-2773177; E-mail: ymansouri@ut.ac.ir

Received October 14, 2010; Accepted November 22, 2010; Published December 24, 2010

Citation: Mansouri YS, Khazaei J, Hassan Beygi SR, Mohtasebi SS (2010) Statistical Modeling of Pomegranate (Punica granatum L.) Fruit with Some Physical Attributes. J Food Process Technol 1:102. doi:10.4172/2157-7110.1000102

Copyright: (c) 2010 Mansouri YS, et al. This is an open-access article distributed under the terms of the Creative Commons Attribution License, which permits unrestricted use, distribution, and reproduction in any medium, provided the original author and source are credited. 
$D g=\sqrt{L W T}$

$S=\pi(D g)^{2}$

sphericity $=\frac{\mathrm{Dg}}{\text { Max length in liner dimension }}$

Where: $\mathrm{L}$ is length of pomegranate fruit $(\mathrm{mm}), \mathrm{W}$ is width of pomegranate fruit $(\mathrm{mm}) ; \mathrm{T}$ is thickness of pomegranate $(\mathrm{mm}), \mathrm{S}$ is surface area $\left(\mathrm{mm}^{2}\right)$ and $D g$ is geometric mean diameter $(\mathrm{mm})$. Meanwhile, height $(\mathrm{h})$ and major diameters $(\mathrm{S}, \mathrm{D})$ of the crown of fruits were measured by using a digital caliper gauge with a sensitivity of 0.01 $\mathrm{mm}$ (Figure 1).

Also, pomegranates' picture was taken by CCD camera (model CANON A85, Japan) that was mounted about $40 \mathrm{~cm}$ above the fruits and projected areas (PA1, PA2 and PA3) in three perpendicular directions of the fruits were calculated by applying the software written in MATLAB 7.1. Criteria projected area (CPA) is defined as [22]:

$$
C P A=\frac{\left(P A_{1}+P A_{2}+P A_{3}\right)}{3}
$$

Spreadsheet software, MINITAB 14, was used to analyze data and determine regression models between the studied parameters

In order to estimate the pomegranate mass from dimensions, projected areas and volume, the following three classifications of models were suggested.

1. Single or multiple variable regressions of pomegranate dimensional characteristics: thickness of fruit (L), major apparent diameter of fruit (W), minor diameter of fruit $(\mathrm{T})$ and geometric mean diameter (Dg).

2. Single or multiple variable regressions of pomegranate projected areas: PA1, PA2 and PA3.

3. Single regression of pomegranate volumes: actual volume, calculated volume of the fruit assumed as oblate spheroid and ellipsoid shapes.

In the case of first classification, mass modeling was accomplished with respect to the thickness, the major and minor diameters, and the geometric mean diameter. Model obtained with four variables for predicting of pomegranate mass was:

$$
M=\alpha L+\beta W+\lambda T+\xi D g+\psi
$$

In this classification, the mass can be estimated as a function of one, two, three and four dimension(s).

In second classification models, mass of pomegranate was estimated based on mutually perpendicular projected areas as following:

$$
M=\alpha P A_{1}+\beta P A_{2}+\lambda P A_{3}+\xi
$$

In this classification, the mass can be estimated as a function of one, two or three projected area(s).
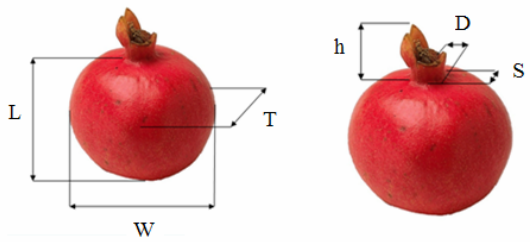

\begin{tabular}{|c|c|c|c|c|c|c|}
\hline \multirow[b]{2}{*}{ Property } & \multicolumn{3}{|c|}{ Hondos yal abad } & \multicolumn{3}{|l|}{ Malas saveh } \\
\hline & Mean $\pm S D$ & Max & Min & Mean $\pm S D$ & Max & Min \\
\hline Major diameter $(\mathrm{mm})$ & $77.24 \pm 6.00$ & 89.64 & 65.01 & $78.16 \pm 7.98$ & 95.87 & 62.11 \\
\hline Intermediate diameter $(\mathrm{mm})$ & $83.71 \pm 6.01$ & 99.53 & 71.25 & $85.37 \pm 8.51$ & 100.52 & 68.83 \\
\hline Minor diameter (mm) & $82.88 \pm 6.28$ & 98.75 & 72.53 & $84.42 \pm 8.30$ & 101.27 & 69.11 \\
\hline Height of crown $(\mathrm{mm})$ & $17.19 \pm 4.69$ & 24.79 & 7.87 & $18.00 \pm 5.53$ & 25.7 & 8.26 \\
\hline Minor diameter of crown $(\mathrm{mm})$ & $15.47 \pm 2.88$ & 25.42 & 11.16 & $18.67 \pm 4.72$ & 33.31 & 11.96 \\
\hline Major diameter of crown $(\mathrm{mm})$ & $15.76 \pm 3.03$ & 25.57 & 11.55 & $18.99 \pm 4.58$ & 32.13 & 12.06 \\
\hline Geometric mean diameter $(\mathrm{mm})$ & $81.22 \pm 5.61$ & 95.86 & 69.51 & $79.02 \pm 7.50$ & 94.73 & 63.86 \\
\hline Sphericity (\%) & $95.8 \pm 0.02$ & 99.4 & 91.1 & $0.91 \pm 0.02$ & 0.94 & 0.85 \\
\hline Mass (g) & $295.29 \pm 62.76$ & 500 & 200.88 & $316.57 \pm 87.5$ & 516.99 & 184.92 \\
\hline Volume $(\mathrm{cm} 3)$ & $239.46 \pm 36.38$ & 300.4 & 176.5 & $374.5 \pm 70.74$ & 411.3 & 158.5 \\
\hline First projected area $(\mathrm{cm} 2)$ & $7.13 \pm 1.25$ & 9.64 & 5.87 & $6.92 \pm 1.42$ & 10.1 & 4.77 \\
\hline Second projected area $(\mathrm{cm} 2)$ & $7.15 \pm 1.10$ & 9.35 & 5.81 & $6.90 \pm 1.47$ & 9.94 & 4.76 \\
\hline Third projected area $(\mathrm{cm} 2)$ & $6.79 \pm 1.04$ & 8.88 & 5.52 & $6.55 \pm 1.40$ & 9.44 & 4.52 \\
\hline
\end{tabular}

Figure 1: Dimensions of pomegranate, three linear dimensions (left) and crown dimension (right)

\begin{tabular}{|c|c|c|c|c|c|}
\hline \multirow[t]{2}{*}{ No. } & \multirow[t]{2}{*}{ Model } & \multicolumn{2}{|c|}{ Malas saveh } & \multicolumn{2}{|c|}{ Hondos yal abad } \\
\hline & & $\mathrm{R}^{2}$ & R.S.E & $\mathrm{R}^{2}$ & R.S.E \\
\hline 1 & $M=\alpha L+\beta$ & 0.78 & 34.79 & 0.44 & 30.64 \\
\hline 2 & $M=\alpha W+\beta$ & 0.93 & 19.71 & 0.62 & 25.98 \\
\hline 3 & $M=\alpha T+\beta$ & 0.91 & 21.68 & 0.85 & 15.68 \\
\hline 4 & $M=\alpha D g+\beta$ & 0.95 & 15.36 & 0.94 & 9.81 \\
\hline 5 & $M=\alpha L+\beta W+\lambda T+\zeta$ & 0.96 & 14.48 & 0.94 & 10.17 \\
\hline 6 & $M=\alpha L+\beta W+\lambda T+\zeta D g+\psi$ & 0.96 & 14.59 & 0.94 & 10.45 \\
\hline 7 & $M=\alpha P A_{1}+\beta$ & 0.65 & 43.86 & 0.5 & 39.99 \\
\hline 8 & $M=\alpha P A_{2}+\beta$ & 0.27 & 63.88 & 0.7 & 39.64 \\
\hline 9 & $\mathrm{M}=\alpha \mathrm{PA}_{3}+\beta$ & 0.27 & 63.88 & 0.7 & 39.62 \\
\hline 10 & $\mathrm{M}=\alpha \mathrm{PA} A_{1}+\beta \mathrm{PA}_{2}+\lambda \mathrm{PA}_{3}+\zeta$ & 0.69 & 42.64 & 0.28 & 37.65 \\
\hline 11 & $M=\alpha V+\beta$ & 0.89 & 24.44 & 0.95 & 9.13 \\
\hline 12 & $M=\alpha V_{\text {elli }}+\beta$ & 0.97 & 12.66 & 0.94 & 9.45 \\
\hline 13 & $M=\alpha V_{\text {osp }}+\beta$ & 0.97 & 12.61 & 0.94 & 9.45 \\
\hline
\end{tabular}

Table 1: Selected physical properties of the two pomegranate varieties (Malas-eSaveh, Hondos-e-Ya abad).

Table 2: Pomegranate mass models based on selected independent variables fo of the two pomegranate varieties (Malas-e- Saveh, Hondos-e-Yal abad).

In the case of the third classification, to achieve models, at first, actual volume $\left(\mathrm{V}_{\mathrm{m}}\right)$ as stated earlier was measured, but because of measuring of actual volume is time consuming task, therefore pomegranate shape was assumed as a regular geometric shape i.e. oblate spheroid $\left(\mathrm{V}_{\text {osp }}\right)$ and ellipsoid $\left(\mathrm{V}_{\text {ellip }}\right)$ shapes, and were calculated as:

$$
\begin{aligned}
& \text { Vopsh }=\frac{\pi}{24} L(W+T)^{2} \\
& V_{\text {ellip }}=\frac{\pi}{6} L W T
\end{aligned}
$$

The performance of the models was evaluated by a set of test data using three different measurements including the root mean square error (RMSE), the coefficient of determination $\left(\mathrm{R}^{2}\right)$ and the mean error (ME) between predicted and measured values [23]. The RMSE or R.S.E is a measure of accuracy and reliability for calibration and test data sets, respectively [24] and is defined as:

$$
R M S E=\sqrt{\left[\frac{1}{n} \sum_{i=1}^{n}\left(M_{p e r, i}-M_{\text {exp }, i}\right)^{2}\right]}
$$

The ME is a measure of bias and reveals the overestimation or underestimation:

$$
M E=\frac{1}{n} \sum_{i=1}^{n}\left(M_{p e r, i}-M_{\exp , i}\right)
$$

Where $M_{\text {per, } i}$ is the $i^{\text {th }}$ predicted mass, $M_{\text {exp }, \mathrm{i}}$ is the $\mathrm{i}^{\text {th }}$ experimental mass, $\mathrm{n}$ is the number of observations. To compare the performance of any two models $\mathrm{M}_{\mathrm{i}}$ and $\mathrm{M}_{\mathrm{i}}$ with respect to $\mathrm{Mi}$, a relative improvement (RI) was calculated:

$$
R I=\frac{R M S E_{M i}-R M S E_{M j}}{R M S E_{M i}} \times 100
$$

Where $\mathrm{RMSE}_{\mathrm{Mi}}$ is highest root mean square error relative to $\mathrm{i}^{\text {th }}$ model and $\mathrm{RMSE}_{\mathrm{Mj}}$ is the root mean square error relative to $\mathrm{j}^{\text {th }}$ model. 


\section{Result and Discussion}

A summary of some selected physical characteristics of the pomegranate fruit and crown are represented in Table 1. They were found for Malas-e-Saveh and Hondos-e-Yalabad pomegranate varieties, at specific fruit moisture contents of 75 and $77 \%$ (w.b), respectively. The models were derived through stepwise method and on the basis of the selected attributes together $\mathrm{R}^{2}$, R.S.E, are presented in Table 2 for Malas saveh and Hondos yal abad varieties, respectively.

\section{First classification models, dimensions}

Among the models Nos. 1-6, shown in Table 2 based on liner dimension, models 4, 5 and 6 for any two varieties had higher $\mathrm{R}^{2}$ and lower R.S.E than models 1-12 while for these models, measurement of three diameters is needed, which make the sizing mechanism more tedious and expensive. Therefore, model 4 , among the one-dimensional models was selected as the best pomegranate mass model with Geometric mean diameter as shown in Figure 2 and Figure 3 for Malas and Hondos varieties, respectively. Tabatabaeefar and Rajabipour (2005) reported an equation calculating apple mass (mixed variety) on the basis of intermediate diameter (b) as $\mathrm{M}=0.08 \mathrm{~b}^{2}-4.74 \mathrm{~b}+5.14$, which is quadratic like the recommended models in the form of Figure 2. They recommended an equation calculating apple mass on the basis of minor diameter as $\mathrm{M}=0.08 \mathrm{c}^{2}-4.74 \mathrm{c}+5.14, \mathrm{R}^{2}=0.89$. Also Khoshnam and et al., (2007) reported that equations to calculate pomegranate mass based on minor diameter had highest $\mathrm{R}^{2}$ value among all the models.

Results showed that all of the mass models of pomegranate fruit based on dimensions were appropriate in the first classification as shown in Table 2.



Figure 2: Pomegranate mass model based on Geometric mean diameter.



Figure 3: Pomegranate mass model based on Geometric mean diameter.

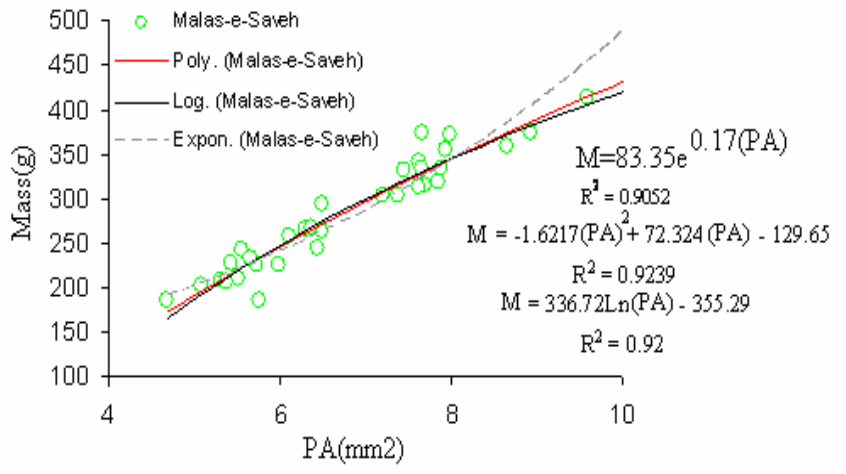

Figure 4: Pomegranate mass model based on one projected area.

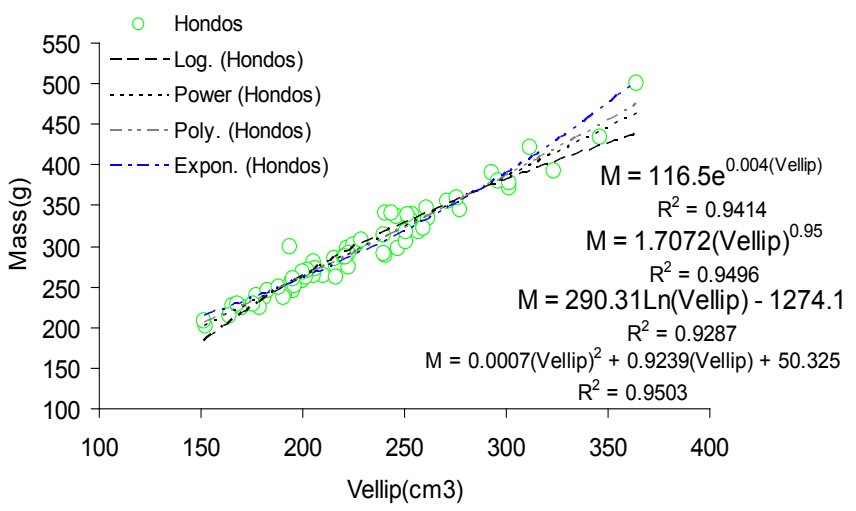

Figure 5: Pomegranate mass model based on ellipsoid $\left(\mathrm{V}_{\text {ellip }}\right)$ shape volume.

\section{Second classification models, projected areas}

The results shown in Table 2 showed that all mass models of pomegranate fruit based on single projected areas has the lowest determining coefficient as 0.5 and highest R.S.E about 39 among models of Table 2. The overall mass model of pomegranate fruit (Malas-e-Saveh variety) based on the one projected area as shown in Figure 4, was given as nonlinear form in following equations:

$$
\begin{aligned}
& \mathrm{M}=-1.62(\mathrm{PA})^{2}-72.32(\mathrm{PA})+231.02, \mathrm{R}^{2}=0.92 \\
& \mathrm{M}=83.35 \mathrm{e}^{0.17(\mathrm{PA})}, \mathrm{R}^{2}=0.90
\end{aligned}
$$

The mass model recommended for sizing kiwi fruits based on any one projected area was reported by Lorestani and Tabatabaeefar (2006) as:

$$
\mathrm{M}=1.098(\mathrm{PC})^{1.273}, \mathrm{R}^{2}=0.97
$$

Where PC is third projected area. Khoshnam and et al., (2007) reported that each one of the three projected areas can be used to estimate the mass. Also, there is a need to have three cameras, in order to take all the projected areas and have one $\mathrm{R}^{2}$ value close to unit or even lower than $\mathrm{R}^{2}$ for just one projected area but results in this study showed that for the two varieties of pomegranate, $\mathrm{R}^{2}$ is too weak.

\section{Third classification models, volume}

Among the models in third classification the $\mathrm{R}^{2}$ for model 12 and 13 had maximum value and minimum R.S.E. According to stepwise method, among mass models on basis volume with single variable, the models based on $M=\alpha V_{\text {ellip }}+\beta$ and $M=\alpha V+\beta$ were the best models for 
malas saveh and Hondos yalabad varieties, which are given in equations 14 and 15 , respectively:

$$
\begin{aligned}
& \mathrm{M}=13.1+1.26 \mathrm{~V} \text { (ellipse) } \\
& \mathrm{M}=26.9+1.17 \mathrm{~V} \text { (ellipse) }
\end{aligned}
$$

Therefore, models 12 and 13 were recommended for predicting pomegranate mass. The mass models of overall pomegranate based on assumed volume as shown in Figure 5.

\section{Conclusion}

In the first classification of single variable mass modeling of pomegranate based on dimension, the highest determining coefficient was obtained as $R^{2}=0.95$ based on geometric mean diameter $M=-528$ $+10.7(\mathrm{Dg})$ while that was as $\mathrm{R}^{2}=0.96$ for multiple variable models (equations No. 6 in Table 2).

There was a very good relationship between mass and measured volume of pomegranates for the two varieties with $R^{2}$ as 0.97 (highest $\mathrm{R}^{2}$ value among all the models).

The model which predicts mass of pomegranates based on estimated volume, the shape of pomegranates considered as spheroid and elliptical were found to be the most appropriate (model 12 and 13 is recommended).

\section{Acknowledgment}

The authors would like to thank University of Tehran for the financial and technical support for this present work.

\section{References}

1. Janatizadeh $A$, Naderi Boldaji $M$, Fatahi $r$, Ghasemi Varnamkhasti $M$, Tbatabaeefar A, et al. (2008) Some Post harvest Physical Properties of Iranian apricot fruit. Int agrophysics 22:356-363.

2. Tabatabaeefar A, Rajabipour A (2005) Modeling the mass of apples by geometrical attributes. Sci Horticulture J 105: 373-382.

3. Khoshnam F, Tabatabaeefar A, Ghasemi Varnamkhasti M, Borghei A (2007) Mass modeling of pomegranate (Punica granatum L.) fruit with some physical characteristics. Sci Horticulture 114: 21-26.

4. Hodgson RW (1917) The pomegranate. Calif Agric Expt Sta Bul 276: 163-192.

5. La Rue JH (1969) Growing pomegranate in California. Univ of Calif Agric Expt Sta Lflt, pp: 305
6. Nagy P, Shaw PE, Wordowski WF (1990) Fruit of Tropical and Subtropica Origin. Florida Science Source, Florida, USA, pp: 328-347.

7. O'Brian M, Floyd S (1978) A microcomputer controlled weighing and print out system for fruit and vegetable grading. Trans ASAE 16:446-450.

8. Pruthi JS, Saxena AK (1984) Studies on anardana (dried pomegranate seeds) J Food Sci Technol 21: 296.

9. Calisir S, Haciseferogullari H, Ozcan M, Arslan D (2005) Some nutritional and technological properties of wild plum (Prunus spp.) fruits in Turkey. $\mathrm{J}$ food eng 66: 233-237.

10. Demir F, Kalyoncu IH (2003) Some nutritional, pomological and physical properties of cornelian cherry (Cornus mas L.). J food eng 60: 335-341.

11. Guleryuz M, Bolat I, Pirlak L (1998) Selection of table cornelian cherry (Cornus mas L.) types in C, oruh valley. Tr. J. of Agriculture and Forestry 22: 357-364.

12. Demir F Ozcan M (2001) Chemical and technological properties of rose (Rosa canina L.) fruits grown wild in Turkey. $\mathrm{J}$ food eng 47: 333-336.

13. Owolarafe OK, Shotonde $\mathrm{HO}$ (2004) Some physical properties of fresh okro fruit. J food eng 63: 299-302.

14. Calisir S, Aydin C (2004) Some physical-mechanical properties of cherry laure (Prunus lauracerasus L.) fruits. J food eng 65: 145-150.

15. Islam A (2002) "Kiraz" cherry laurel (Prunus laurocerasus). N Z J Crop Hortic Sci 30: 301-302

16. Topuz A, Topakci M, Canakci M, Akinci i, Ozdemir F (2005) Physical and nutritional properties of four orange varieties. J food eng 66: 519-523.

17. Khazaei J, Mann DD (2004) Effects of temperature and loading characteristics on mechanical and stress-relaxation properties of sea buckthorn berries. Part 1. Compression tests. Ejournal CIGR 6: Manuscript FP 03011.

18. Akinci I, Ozdemir F, Topuz A, Kabas O, Anakci C (2004) Some physical and nutritional properties of Juniperus drupacea fruits. J food eng 65: 325-331.

19. Sitkei G (1986) Mechanics of Agricultural Materials. Elsevier Science Pub Co Inc, 52 Vanderbilt Ave, New York, NY 10017. P: 25

20. Frechette R, Zahradnik J (1968) Thermal properties of Mc Intosh apple. Trans ASAE 11: 21-24

21. AOAC (1984) Official Methods of Analysis. Association of Official Analytica Chemists Press, Washington, DC

22. Mohsenin N N (1986) Physical properties of Plant and Animal Materials. (2ndedn), Gordon and Breach Sci publ., New York.

23. Amini M, Abbaspour KC, Khademi H, Fathianpour N, Afyuni M, et al, (2005) Neural network models to predict cation exchange capacity in arid regions of Iran. Soil Science Euro J 56: 551-559.

24. Cihan A, Kahveci K, Hacihafizoĝlu (2007) Modeling of intermittent drying of thin layer rough rice. Food Eng J 79: 293-298. 